\title{
Nasal Schwannoma Presented as External Nasal Swelling: A Rare Case Presentation
}

\author{
Vishal Vasant Jain ${ }^{1}$, Harish Khatakdhond ${ }^{2}$, Kunzang Bhutia ${ }^{3}$
}

\begin{abstract}
Introduction: Nasal schwannomas are very rare neoplasms. According to the literature, half of the schwannoma cases occur in the head and neck areas and only $<4 \%$ occur in the sinonasal tract. So far, only a few cases have been reported.

Case description: We present the case of a 50-year-old man who had dorsal nasal deformity at the root of nose since 5 months. Complete excision of mass was performed by giving dorsal incision through external approach under local anesthesia. Here, we discuss the clinical and pathological aspects of schwannomas arising at dorsum of nose.

Conclusion: Although schwannoma of the nose is extremely rare, the possibility of their existence should be realized and included in the differential diagnosis of any dorsal nasal mass.

Keywords: Nasal deformity, Neurilemmoma, Schwannoma.

Otorhinolaryngology Clinics: An International Journal (2019): 10.5005/jp-journals-10003-1328
\end{abstract}

\section{INTRODUCTION}

Schwannomas or neurilemmomas are neurogenic tumors arising from Schwann cells of the neural sheath of the peripheral, cranial, or autonomic nerves. 'Schwannoma commonly occurs in the head and neck regions and extremities, ${ }^{2}$ but nasal schwannoma is extremely rare. It accounts for $<4 \%$ of benign solitary schwannoma of the head and neck region. ${ }^{3}$ Few cases and very few case series were reported till date. Origin of sinonasal schwannoma from ophthalmic and maxillary branches of trigeminal nerve and branches of autonomic nerve has been postulated. ${ }^{4}$ In this article, we describe our reported case of a nasal schwannoma presenting initially with dorsal nasal deformity.

\section{Case Description}

A 50-year-old male patient presented to us in the Department of ENT, Rajawadi Hospital, Ghatkopar, Mumbai, with the history of swelling over the root of nose since 5 months (Fig. 1). There was no history of any nasal obstruction, epistaxis, and rhinorrhea. History of nasal trauma present at same site 6 months ago. His vision was normal and had normal eye movements. There was no skin lesion/ pigmentation over his any body part and had no signs of focal neurological deficits. Local examination revealed smooth $5 \times 4 \times$ $2 \mathrm{~cm}$ swelling at the root of nose and bony nasal dorsum causing nasal deformity and telecanthus. The skin over swelling was normal and on palpation it was firm, nontender, non-fluctuant, and noncompressible. On anterior rhinoscopy, there was no any intranasal extension and no any mass seen.

Contrast-enhanced high-resolution computed tomography (HRCT) of the paranasal sinuses revealed soft tissue expansile lesion of $52 \times 44 \times 22 \mathrm{~mm}$ size in the left side at the root of nose. All paranasal sinuses were clear. There was no any extension to the orbital region or any intracranial extension. Fine needle aspiration cytology showed only blood.

Patient was posted for complete excision surgery under local anesthesia with proper consent. Local infiltration with $2 \%$ xylocaine with adrenaline was given. A left-sided modified lateral
${ }^{1-3}$ Department of ENT, Rajawadi Hospital, Mumbai, Maharashtra, India Corresponding Author: Vishal Vasant Jain, Department of ENT, Rajawadi Hospital, Mumbai, Maharashtra, India, Phone: +91 8180946965, e-mail: vishal1851987@gmail.com

How to cite this article: Jain VV, Khatakdhond H, Bhutia K. Nasal Schwannoma Presented as External Nasal Swelling: A Rare Case Presentation. Int J Otorhinolaryngol Clin 2019;11(1):12-14.

Source of support: Nil

Conflict of interest: None

rhinotomy skin incision was made over swelling. On flap elevation, a well-circumscribed, lobulated mass found adherent to the left side lateral nasal bone was excised completely in toto (Fig. 2). Skin flaps sutured after securing hemostasis. Specimen was sent for histopathological report (Fig. 3).

Histopathological examination of the excised specimen came up with a final diagnosis of benign schwannoma. The examination

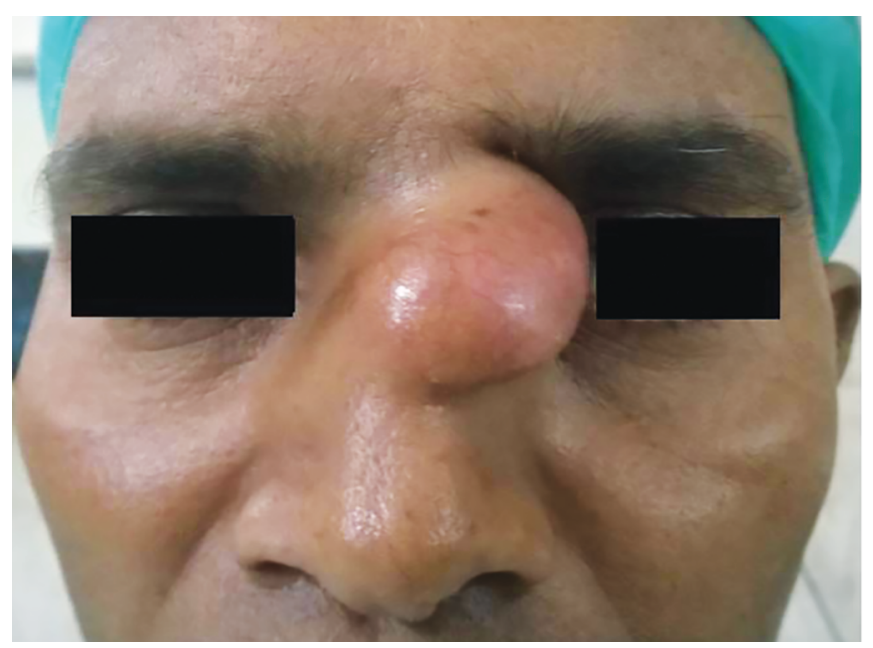

Fig. 1: Preoperative clinical photograph

o The Author(s). 2019 Open Access This article is distributed under the terms of the Creative Commons Attribution 4.0 International License (https://creativecommons. org/licenses/by-nc/4.0/), which permits unrestricted use, distribution, and non-commercial reproduction in any medium, provided you give appropriate credit to the original author(s) and the source, provide a link to the Creative Commons license, and indicate if changes were made. The Creative Commons Public Domain Dedication waiver (http://creativecommons.org/publicdomain/zero/1.0/) applies to the data made available in this article, unless otherwise stated. 


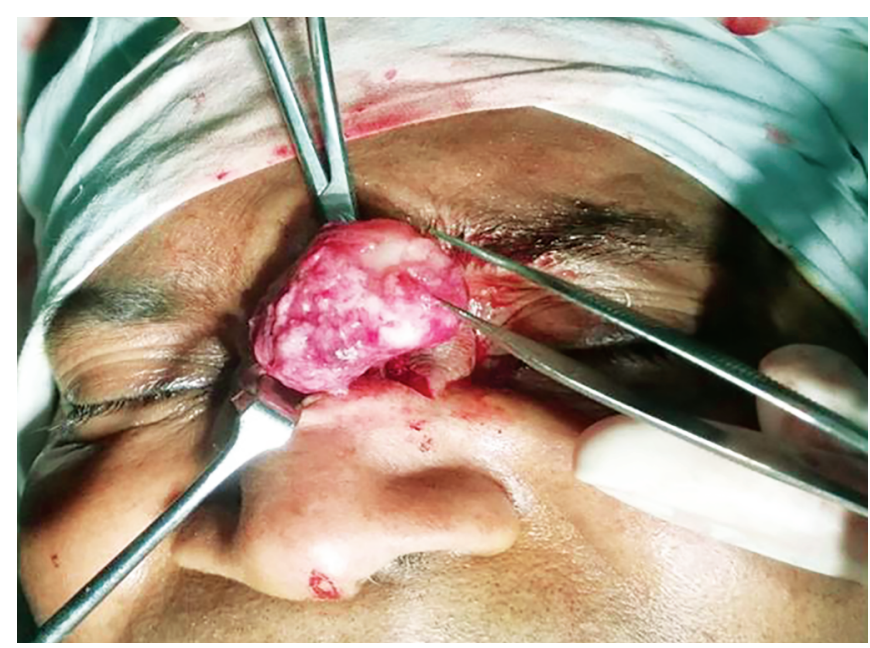

Fig. 2: Complete mass excision under local anesthesia

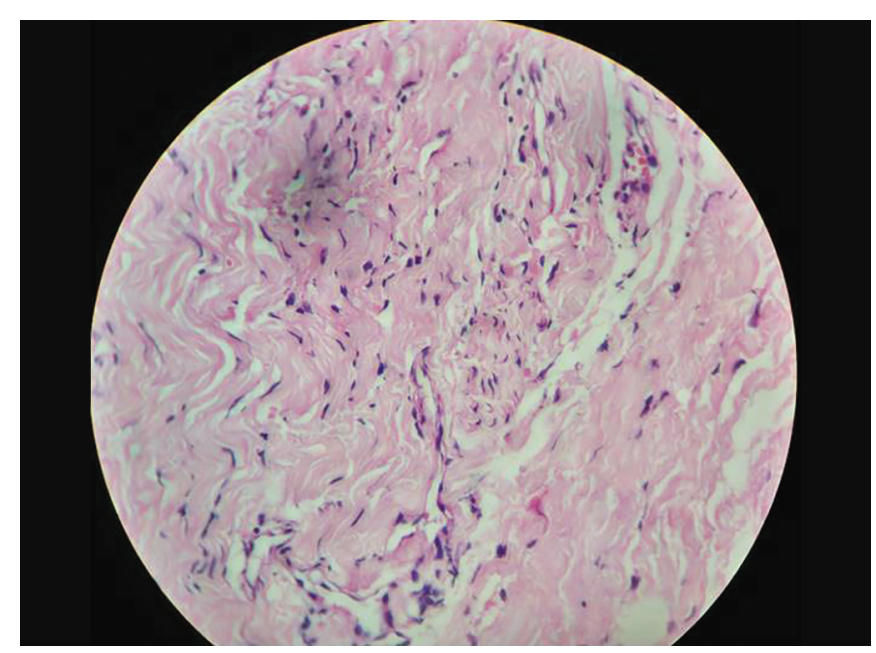

Fig. 4: Histopathological examination of specimen showing Antoni A and Antoni B cells suggestive of schwannoma

revealed a soft tissue tumor formed of alternating zones of compact spindle cells arranged in interlacing fascicles (Antoni A) and loose hypocellular zones (Antoni B) (Fig. 4). The nuclei in the more cellular areas were arranged in a palisaded pattern (Verocay bodies). No evidence of malignancy was found.

Postoperative recovery was uneventful (Fig. 5) and, at 4 month follow-up, there is no evidence of disease and skin incision is well healed.

\section{Discussion}

Nasal schwannomas are very uncommon neoplasms. They have been postulated to arise from the ophthalmic or maxillary divisions of the trigeminal nerve, the sympathetic fibers from the carotid plexus, or the parasympathetic fibers from the sphenopalatine ganglion. ${ }^{5}$ It was difficult to find out the nerve of origin of the tumor in our case but probably it was infratrochlear nerve branch of nasociliary nerve (due to its site). It can present at any age with no sex or race predisposition and local recurrences are infrequent.

Sinonasal schwannoma is a slowly growing mass. Symptoms depend on the location of the tumor and usually it presents with

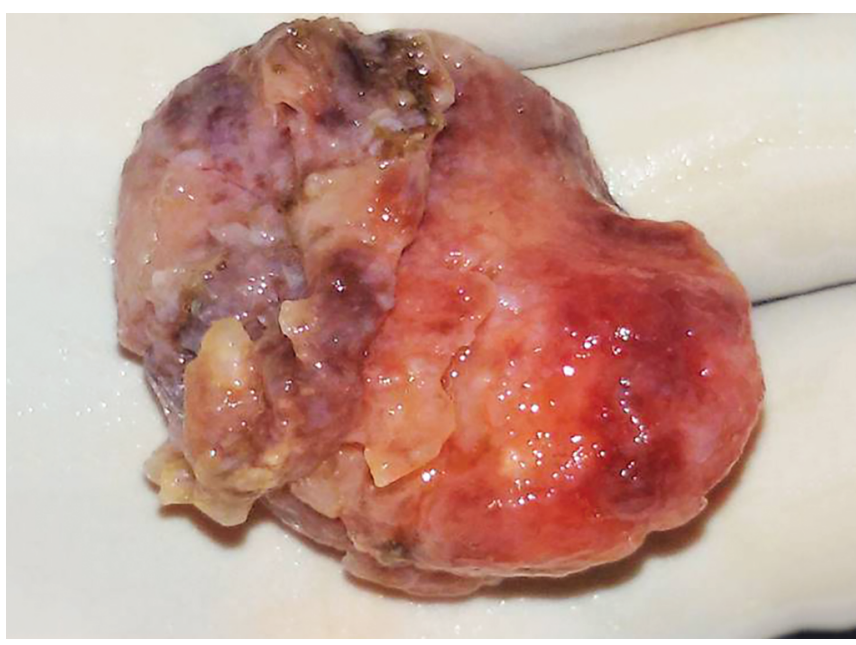

Fig. 3: Excised specimen sent for histopathological report

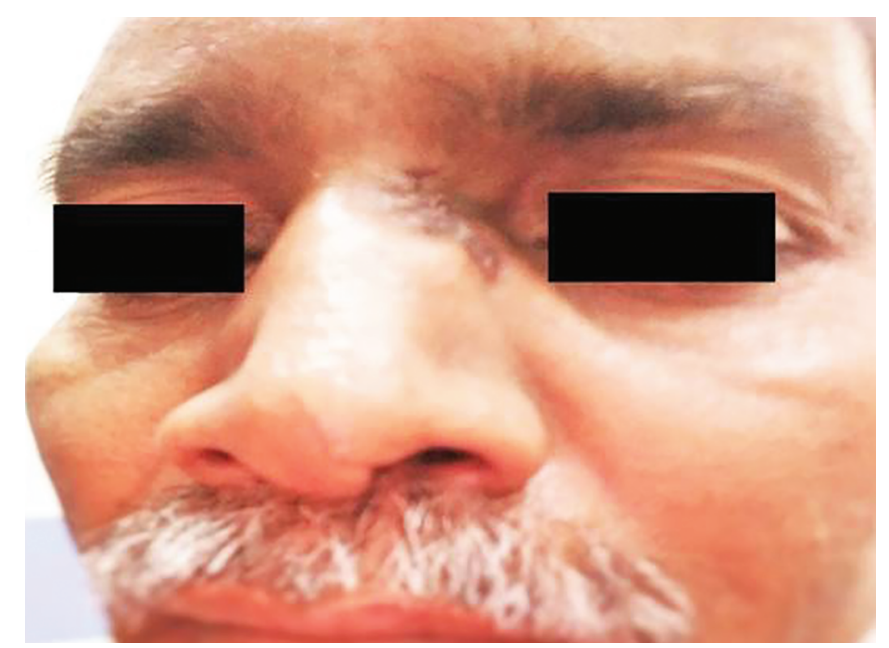

Fig. 5: Postoperative day 7 image

progressive nasal obstruction with or without epistaxis, anosmia/ hyposmia, facial swelling, headache, and in long-standing cases, it may cause proptosis or bony erosion due to pressure effect and may lead to intracranial extension. Epistaxis is common in tumors of the ethmoid sinus and nasal fossae, while pain was related to lesions of the maxillary sinus. ${ }^{6}$

CT scan is usually sufficient for delineating the extent of benign schwannomas and outlining the bony margins to rule out the invasion. However, MRI is useful for the delineation of intracranial or intraorbital tumor extension and compared with CT, MRI can better evaluate the cause of opacified sinuses (e.g., tumor or inflammation). Sinonasal schwannomas have an intermediate to high intensity on T1-weighted images and the T2-weighted signal depending on the cellularity of the lesion and the cystic characteristics of the lesion. ${ }^{1}$

The differential diagnosis includes a spectrum of lesions ranging from angiomas and polyps to malignant tumors, such as melanoma or olfactory neuroblastoma. Since it is an expansile lesion without bone destruction, it can be differentiated from malignancy and shows enhancement in CT unlike a mucocele. In 1920, Antoni ${ }^{7}$ described the histological aspect of this tumor distinguishing two alternating histological patterns: Antoni type 
A (fasciculated pattern) and type B (reticular pattern). Antoni type $A$ areas are composed of compact spindle cells arranged in short or interlacing fascicles. Areas of nuclear palisading with nuclear alignment in rows are known as Verocay bodies. Antoni type $B$ areas are composed of few spindle cells loosely arranged in a fibrillar myxoid stroma. ${ }^{8}$ Electron microscopy and immunohistochemical analysis ( 1100$)$ are necessary to differentiate a schwannoma from a neurofibroma.

Most schwannomas are progressively growing tumors that eventually require treatment. Surgical excision remains the treatment of choice and the tumor can be excised without compromising the nerve function. The approach for the resection should be chosen according to the location and extension of the tumor. The aim is to have (i) adequate exposure and (ii) good cosmetic appearance, which is probably the most important from patient's viewpoint. Various combinations of techniques, including lateral rhinotomy, external ethmoidectomy, Caldwell-Luc approach, midface degloving, and endonasal endoscopic resection, can be used. ${ }^{9,10}$ In our case, a left-sided modified lateral rhinotomy skin incision was made over swelling and complete excision of tumor was performed.

\section{Conclusion}

We report a 50-year-old male patient with schwannoma at the root of nose at nasion region which was successfully treated with complete surgical excision under local anesthesia. Although schwannoma of the nose is extremely rare, the possibility of their existence should be realized and included in the differential diagnosis of any dorsal nasal mass.

\section{Reference}

1. Younis RT, Gross CW, Lazar RH. Schwannomas of the paranasal sinuses. case report and clinicopathologic analysis. Arch Otolaryngol Head Neck Surg 1991;117(6):677-680. DOI: 10.1001/ archotol.1991.01870180113022.

2. Weiss SW, Goldblum JR. Enzinger and Weiss's Soft Tissue Tumors. 5th ed.

3. Das Gupta TK, Brasfield RD, Strong EW, et al. Benign solitary schwannomas (neurilemomas). Cancer 1969;24(2):355-366. DOI: 10.1002/1097-0142(196908)24:2<355::AID-CNCR2820240218>3.0. $\mathrm{CO} ; 2-2$.

4. Ross C, Wright E, Moseley J, et al. Massive schwannoma of the nose and paranasal sinuses. South Med J 1988;81(12):1588-1591. DOI: 10.1097/00007611-198812000-00032.

5. Hegazy HM, Snyderman $\mathrm{CH}$, Fan $\mathrm{CY}$, et al. Neurilemmomas of the paranasal sinuses. Am J Otolaryngol 2001;22(3):215-218. DOI: 10.1053/ ajot.2001.23434.

6. RobitailleY, SeemayerTA, EI Deiry A. Peripheral nerve tumors involving paranasal sinuses: a case report and review of the literature. Cancer 1975;35(4):1254-1258.DOI: 10.1002/1097-0142(197504)35:4<1254::AIDCNCR2820350433>3.0.CO;2-3.

7. Antoni NRE. About spinal cord tumors and neurofibromas. Munich: JF Bergmann publishing house; 1920. pp. 413-423.

8. Suh JD, Ramakrishnan VR, Zhang PJ, et al. Diagnosis and endoscopic management of sinonasal schwannomas. J Otorhinolaryngol Relat Spec 2011;73(6):308-312. DOI: 10.1159/000331923.

9. Lee JH, Bae JH, Kim KS. A case of solitary neurofibroma of the nasal dorsum: resection using an external rhinoplasty approach. Eur Arch Otorhinolaryngol 2005;262(10):813-815. DOI: 10.1007/s00405-0050915-4.

10. Donnelly MJ, Al-sader MH, Blaney AW. Benign nasal schwannoma: view from beneath: pathology in focus. J laryngol Otol 1992;106(11): 1011-1015. DOI: 10.1017/S0022215100121644. 